\title{
Physical Activity Intolerance and Cardiorespiratory Dysfunction in Patients with Moderate-to-Severe Traumatic Brain Injury
}

\author{
Renee N. Hamel ${ }^{1,2}$ (D . James M. Smoliga ${ }^{1}$ (D)
}

Published online: 16 May 2019

C) Springer Nature Switzerland AG 2019

\begin{abstract}
Moderate-to-severe traumatic brain injury (TBI) is a chronic health condition with multi-systemic effects. Survivors face significant long-term functional limitations, including physical activity intolerance and disordered sleep. Persistent cardiorespiratory dysfunction is a potentially modifiable yet often overlooked major contributor to the alarmingly high long-term morbidity and mortality rates in these patients. This narrative review was developed through systematic and non-systematic searches for research relating cardiorespiratory function to moderate-to-severe TBI. The literature reveals patients who have survived moderate-to-severe TBI have 25-35\% reduction in maximal aerobic capacity 6-18 months post-injury, resting pulmonary capacity parameters that are reduced $25-40 \%$ for weeks to years post-injury, increased sedentary behavior, and elevated risk of cardiorespiratory-related morbidity and mortality. Synthesis of data from other patient populations reveals that cardiorespiratory dysfunction is likely a consequence of ventilator-induced diaphragmatic dysfunction (VIDD), which is not currently addressed in TBI management. Thus, cardiopulmonary exercise testing should be routinely performed in this patient population and those with cardiorespiratory deficits should be further evaluated for diaphragmatic dysfunction. Lack of targeted treatment for underlying cardiorespiratory dysfunction, including VIDD, likely contributes to physical activity intolerance and poor functional outcomes in these patients. Interventional studies have demonstrated that short-term exercise training programs are effective in patients with moderate-to-severe TBI, though improvement is variable. Inspiratory muscle training is beneficial in other patient populations with diaphragmatic dysfunction, and may be valuable for patients with TBI who have been mechanically ventilated. Thus, clinicians with expertise in cardiorespiratory fitness assessment and exercise training interventions should be included in patient management for individuals with moderate-to-severe TBI.
\end{abstract}

\section{Introduction}

Traumatic brain injury (TBI) is a major public health crisis that affects all demographics and impacts approximately half of the world's population $[1,2]$. After initial injury, TBI has significant long-term consequences, supporting its conceptualization as a chronic health condition. Among adolescents and adults who received rehabilitation for moderateto-severe TBI, mortality rate is six times higher 13 years post-TBI, life expectancy is shortened by 6-7 years, and nearly four in ten will demonstrate a significant decline in function from the level of recovery attained 1-2 years after

Renee N. Hamel

rhamel@highpoint.edu

1 Department of Physical Therapy, One University Parkway, High Point University, High Point, NC 27268, USA

2 School of Physiotherapy, University of Otago, 325 Great King St., North Dunedin, Dunedin 9016, New Zealand injury [2-4]. Additionally, survivors of TBI face a number of other impairments, including physical activity intolerance, fatigue, emotional and behavioral changes, and disordered sleep $[5,6]$. Thus, there is a clear need to address these factors, which contribute to significant morbidity and mortality in survivors $[7,8]$.

Cardiorespiratory dysfunction and exercise intolerance in patients with TBI have been described in the literature [9-13] but have generally not been a priority in patient management, and the long-term consequences of these issues remain largely overlooked. Cardiorespiratory dysfunction in the moderate-to-severe TBI population is rooted in a combination of physical deconditioning and changes in contractility and atrophy of the diaphragm in those who have been mechanically ventilated during the acute phase of TBI management. Patients with a history of moderate-to-severe TBI display similar cardiorespiratory changes, co-morbidities, and functional deficits to patients with known diaphragmatic dysfunction [14-17], as well as those who have received long-term ventilation [18-21]. These morbidities contribute 


\section{Key Points}

A small but growing number of studies demonstrate that patients with moderate-to-severe traumatic brain injury (TBI) commonly experience physical activity intolerance and impaired cardiorespiratory function, and have increased risk of cardiorespiratory-related co-morbidities and elevated mortality.

Maximal aerobic capacity is severely diminished (mean $24.6 \mathrm{~mL} \mathrm{O} / \mathrm{kg} / \mathrm{min}, \sim 5$ th percentile) and submaximal cardiorespiratory responses are abnormal for weeks to years following moderate-to-severe TBI, which may be responsible for the sedentary behavior common in this population.

A few studies directly address this issue, but ventilatorinduced diaphragmatic dysfunction and its sequelae are generally not addressed in patients with moderate-tosevere TBI, despite their history of mechanical ventilation during the acute phase of care.

A number of interventional studies have demonstrated that short-term exercise training programs are effective in patients with moderate-to-severe TBI, but are generally not sufficiently emphasized at any point of rehabilitation.

Synthesis of the available evidence suggests that recognition and proper management of cardiorespiratory dysfunction in patients with moderate-to-severe TBI has potential to substantially improve patient outcomes and quality of life, and long-term interventional studies are necessary to confirm this.

to various functional deficits including decreased activity tolerance and participation restrictions, which are common in the sub-acute and chronic phases of recovery from TBI. Additionally, these morbidities increase the mortality rate in this population. While the long-term health issues related to mechanical ventilation [22, 23] and extended hospital stays $[24,25]$ are well-documented, inpatient and long-term rehabilitation strategies for patients with TBI do not adequately target cardiorespiratory outcomes. Thus, the purpose of this narrative review is to synthesize available research regarding the contributors to and management of cardiorespiratory dysfunction following moderate-to-severe TBI.

\section{Search Methodology}

A systematic review was originally attempted to capture all literature on the topic relating TBI to cardiorespiratory dysfunction. The following search strategy was utilized on
PubMed, PsycINFO and CINAHL in the attempt to comprehensively identify the original research on this topic: ("traumatic brain injury" OR "TBI" OR "brain trauma” OR "head injury” OR "brain injury”) AND (dyspnea OR dyspneic OR dyspnoea OR dyspnoeic OR breathless OR breathlessness OR "short of breath" OR "shortness of breath" OR "respiratory distress" OR hypoxemia OR hypoxemic OR hypoxaemia OR hypoxaemic OR desaturation OR desaturate OR "pulse oximeter" OR "pulse oximetry" OR “oxygen saturation" OR "hemoglobin saturation" OR "haemoglobin saturation" OR " $\mathrm{PAO}_{2}$ " OR " $\mathrm{SAO}_{2}$ " OR exercise OR "physical activity" OR exertion OR deconditioned OR deconditioning OR decondition OR aerobic OR endurance OR ventilator OR breathing OR respiratory OR respiration OR inhale OR inhalation OR inspiratory OR inspiration OR diaphragm OR diaphragmatic OR pulmonary OR ventilatory OR ventilation OR VIDD OR spirometry OR spirometer OR lung OR intubation OR intubated OR intubate OR tracheotomy OR tracheostomy OR extubation OR extubate OR extubated OR diaphragm OR diaphragmatic OR spirometry OR spirometer OR cardiac OR cardiorespiratory OR cardiorespiratory OR cardiovascular).

While many results were obtained, thorough screening of titles and abstracts by both authors revealed very few relevant original research articles that specifically examined the connection between moderate-to-severe TBI and cardiorespiratory dysfunction. The relevant articles identified by this search strategy also did not fit into discrete categories. The relative dearth of literature directly relating cardiorespiratory dysfunction and moderate-to-severe TBI reflects a lack of attention to this topic, both in research settings and clinical practice. As such, the authors opted to utilize a narrative review format, which includes some literature from other (i.e., non-TBI) patient populations, and synthesize this evidence to demonstrate that persistent cardiorespiratory dysfunction is present and has significant deleterious effects in patients who survive a moderate-to-severe TBI.

\section{Contributors to Physical Activity Intolerance and Cardiorespiratory Dysfunction}

\subsection{Hospital-Acquired Deconditioning}

Patients with moderate-to-severe TBI undergo lengthy inpatient hospital and rehabilitation center stays during which they are largely physically inactive [26, 27]. Such prolonged inactivity, including bed rest and other sedentary behaviors, combined with sleep disturbances and nutritional deficits, leads to hospital-acquired deconditioning (HAD) [24, 25], which is a factor in post-hospital syndrome [28]. Catabolic changes in muscle during this time ultimately lead to an 
overall decrease in physical fitness, including muscular strength and cardiorespiratory endurance [24]. The magnitude of dysfunction is often beyond that expected from immobilization itself [29], which suggests that a history of mechanical ventilation also likely exacerbates HAD.

\subsection{Ventilator-Induced Diaphragmatic Dysfunction}

A majority of individuals with moderate TBI and all persons with severe TBI receive mechanical ventilation as part of required life-saving standards of care [27]. It is wellestablished that those who undergo mechanical ventilation for $>24 \mathrm{~h}$ can experience lung injuries and ventilatorinduced diaphragmatic dysfunction (VIDD) [22, 30]. VIDD ultimately impairs cardiorespiratory function in human and animal models [23, 31, 32]. Though VIDD has received much attention in patients undergoing critical care [33, 34], it receives little attention in the moderate-to-severe TBI population despite their prolonged mechanical ventilation. While studies examining VIDD often do not report the specific medical condition that led to mechanical ventilation, Levine's landmark study characterizing VIDD in humans includes brain dead subjects, of which presumably some were due to TBI (i.e., motor vehicle accidents) [18, 22].

VIDD is characterized by protein degradation in myofibrils of the diaphragm through the ATP-dependent ubiquitin-proteasome pathway [22]. Mechanical ventilation increases oxidative stress in the diaphragm, causing decreased protein synthesis and increased activity of proteolytic pathways, further accelerating the atrophy process $[35,36]$. Animal model research has demonstrated that neuromuscular-blocking agents commonly used in the intensive care unit may also exacerbate this degradation [37], though it is unknown how this translates to mechanically ventilated humans. As few as 12-18 h of mechanical ventilation can result in significant diaphragm atrophy and contractile dysfunction, with longer durations causing more severe muscle injury [22, 38-40]. VIDD can quickly become a 'downward spiral' due to the systemic implications that result from diaphragmatic atrophy and weakness [39]. VIDD may also progress and become seemingly irreversible, causing significant cost in terms of both healthcare dollars and lives [39].

Diaphragmatic weakness and dysfunction ultimately decrease inspiratory pressure [22]. This causes significant deterioration of pulmonary function in patients with poor cardiorespiratory reserve and may lead to secondary complications, including hypoxemia, pneumonia, and prolonged dependence on a ventilator [41]. Additionally, observational studies have consistently demonstrated that diaphragmatic dysfunction is associated with various sleep disturbances $[14,15,42]$, which also impact long-term quality of life. The consequences of impaired ventilatory capacity rooted in VIDD and HAD are magnified when metabolic demands are increased beyond resting values, leading to fatigue and physical activity intolerance [16]. Therefore, unaddressed cardiorespiratory dysfunction due to unrecognized VIDD likely causes or exacerbates other common co-morbidities, contributes to poor clinical outcomes, and significantly impairs quality of life.

Prevention of VIDD would likely have a significant impact on morbidity, mortality, and cost of TBI care of critically ill individuals. Unfortunately, VIDD cannot be easily prevented in patients with moderate-to-severe TBI because mechanical ventilation is absolutely necessary in the acute stages of care. New strategies to attenuate diaphragmatic dysfunction during ventilation, such as phrenic nerve stimulation [43], may be of value in the future but are not common practice at this time.

\section{Clinical Indicators of Cardiorespiratory Dysfunction in Patients with a History of Moderate-to-Severe Traumatic Brain Injury (TBI)}

A summary of the evolution and sequelae of cardiorespiratory dysfunction in patients with TBI is presented in Fig. 1.

\subsection{Fatigue}

The chief indicator of cardiorespiratory dysfunction in patients with moderate-to-severe TBI is physical activity intolerance, which is often conflated with the broader symptom of 'fatigue'. The general symptom of 'fatigue' is prevalent in the TBI population and is generally attributed to primary central nervous system dysfunction and sleeprelated issues [44-47]. However, the combination of VIDD and HAD results in cardiorespiratory dysfunction and few resources consider the relevance of cardiorespiratory dysfunction in fatigue [48]. As such, it is necessary for clinicians to differentiate this physical activity intolerance from a sense of general tiredness when considering factors related to 'fatigue' in this patient population.

\subsection{Sedentary Lifestyle}

Following moderate-to-severe TBI, patients often adopt a sedentary lifestyle [49], which ultimately impairs long-term health. The literature on physical activity levels following TBI is relatively scant, but a recent systematic review identified six studies on the topic, which consistently demonstrated insufficient activity for health maintenance across a wide range of post-injury timepoints [50]. Cross-sectional studies have revealed post-TBI decreases in physically demanding physical activities [51] and discontinuation of sports participation in exchange for sedentary behaviors 
[49]. While physical activity interventions have consistently been demonstrated to improve functional outcomes in patients with TBI [52], persistent cardiorespiratory dysfunction may serve as a key barrier to patients engaging in regular physical activity.

\subsection{Disordered Sleep}

Patients with a history of moderate-to-severe TBI frequently experience disordered sleep, including obstructive sleep apnea and restlessness [5, 6]. A number of studies have identified that patients with moderate-to-severe TBI report poor sleep quality [53-55], insomnia [56], and sleep-wake cycle disturbances [57, 58]. Three years following mild-to-severe TBI, two-thirds of patients still report various sleep-wake cycle disturbances, which seem to be independent of severity and localization of TBI [59]. Polysomnography also demonstrates abnormal sleep parameters in this patient population (e.g., changes in deep sleep and rapid eye movement sleep, more awakenings during sleep) [53, 60-62], and that these types of changes are more pronounced in patients with moderate-to-severe TBI than those with mild TBI [63]. These issues overlap considerably with common symptoms of VIDD [64], and it is likely that the presence of VIDD may underlie and/or exacerbate neurologic factors that cause sleep disturbance. Indeed, cross-sectional studies and case series have revealed that sleep disturbances are also common in individuals with diaphragmatic dysfunction $[6,14,15$, $65,66]$, which can result in nocturnal hypoxia [42]. Though polysomnography has been part of some TBI research, it is not a routine part of patient evaluation [47].

\subsection{Cardiorespiratory Disease}

Evidence is beginning to emerge which demonstrates that cardiovascular co-morbidities are common in patients with TBI, though epidemiological studies remain limited. One retrospective cohort study of inpatient rehabilitation centers ( $n=1791$ patients with TBI) revealed $34.5 \%$ of males and $50.4 \%$ of females experienced circulatory system co-morbidities [7]. Another retrospective cohort study $(n=2320)$ identified that cardiorespiratory diseases are among the most common causes of 1 - to 5-year post-injury mortality in the TBI population, even in those who are fully ambulatory [8]. It remains unknown how much primary cardiorespiratory dysfunction (e.g., HAD and VIDD) contributes to these factors compared to neurologic dysfunction (e.g., blood pressure regulation).

Acute lung injury is also relatively common following isolated TBI [67], and poor lung function can directly impact brain oxygenation [68]. Indeed, respiratory distress and hypoxia cause agitation and restlessness [69], which are common in the sub-acute phase of TBI recovery. While cognitive and behavioral impairments following TBI are directly

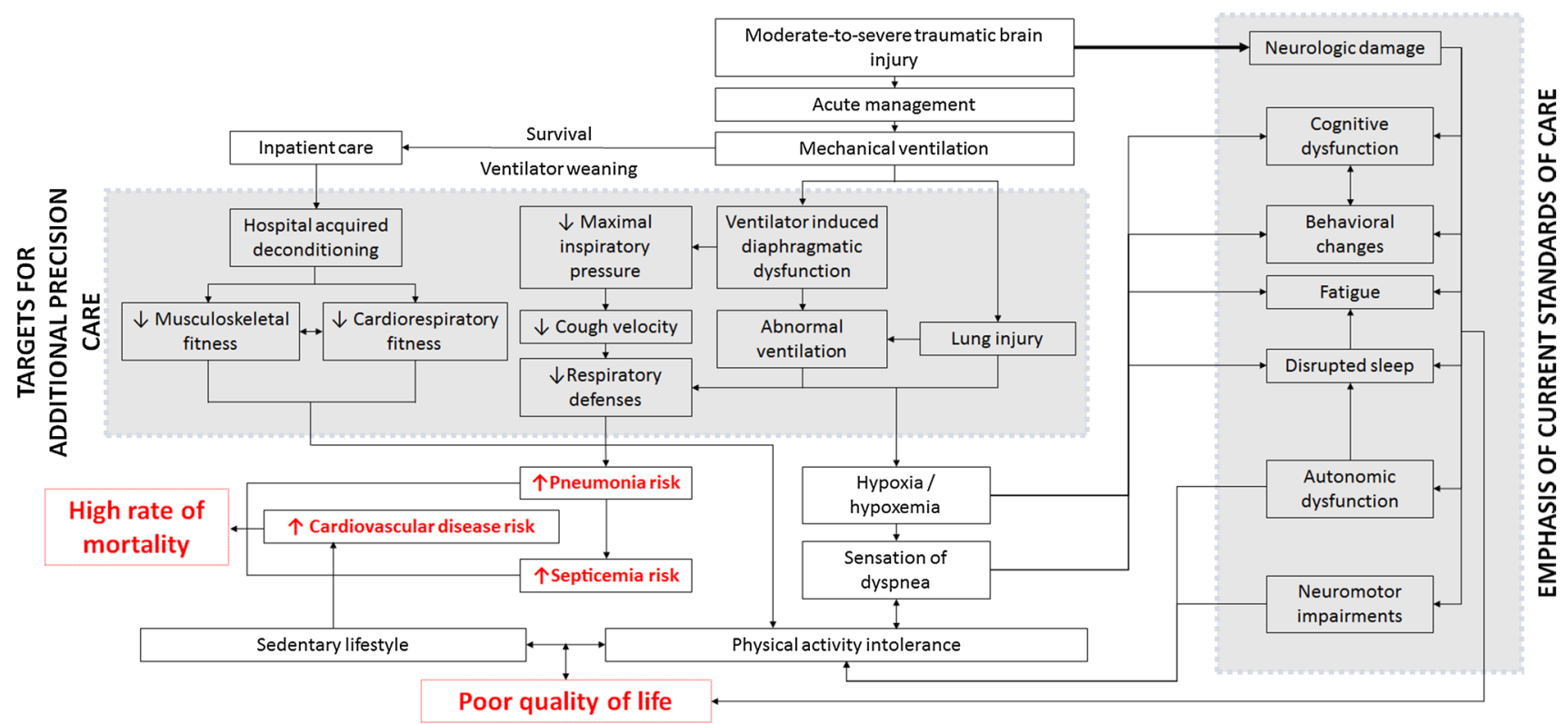

Fig. 1 Evolution and consequences of cardiorespiratory dysfunction in patients with moderate-to-severe traumatic brain injury (TBI). The current standards of care for moderate-to-severe TBI focus on addressing neurological damage. However, many of these neurological complications are likely exacerbated by the persistent effects of insufficiently addressed ventilator-induced diaphragmatic dysfunc- tion. Precision care that aggressively targets cardiorespiratory dysfunction in individuals with TBI may attenuate some of the medical complications and co-morbidities experienced in this population which are responsible for significant morbidity and high mortality rates. This will ultimately reduce the cost of healthcare and improve quality of life in these patients 
attributable to brain trauma, it is possible they may also be exacerbated by cardiorespiratory-related hypoxia (including nocturnal hypoxia [see Sect. 4.3]).

\subsection{Infectious Disease}

Chronically impaired ventilation may also substantially impair the respiratory system's defenses against infectious disease. Individuals who survive more than 1 year after moderate-to-severe TBI are 12 times more likely to die from septicemia, four times more likely to die from pneumonia, and three times more likely to die from other respiratory disorders than a matched control group from the general population [70]. This is consistent with data from acutely ill patients who received mechanical ventilation, who also have high rates of morbidity and mortality from secondary complications attributed to cardiorespiratory dysfunction [29]. Inability to generate strong inspiratory pressures due to VIDD may ultimately impair the effectiveness of coughing and other respiratory-mediated defenses, thereby raising the risk of pneumonia, similar to what has been described in patients with stroke [71].

\subsection{Autonomic Nervous System Dysfunction}

Patients with TBI may develop autonomic nervous system dysfunction, most commonly known as autonomic dysreflexia and dysautonomia [72]. Autonomic nervous system dysfunction ultimately results in impaired regulation of blood pressure and regional blood flow, both at rest and during exercise, and is therefore inter-related to other aspects of cardiorespiratory dysfunction. Clinical signs of autonomic dysregulation frequently include tachycardia, tachypnea, hypertension, and impaired thermoregulation [72]. Various aspects of autonomic nervous system dysfunction appear to begin immediately in the acute stages of TBI [73] and persist into the sub-acute stage [74]. There is some evidence that measurements of autonomic nervous system function during the acute stage of injury can predict long-term outcomes and mortality in patients with moderate-to-severe TBI [75-78]. Although autonomic nervous system dysfunction does appear to improve during recovery [79], it often remains present in the chronic stages [80] of TBI. Additionally, autonomic nervous system dysfunction has been demonstrated following prolonged periods of mechanical ventilation in the general patient population [81].

\section{Evaluation of Cardiorespiratory Dysfunction in Patients with Moderate-to-Severe TBI}

Accurate diagnosis in patients recovering from moderate-tosevere TBI may be challenging due to cognitive or behavioral issues which impair one's ability to accurately selfreport symptoms indicative of cardiorespiratory dysfunction. Therefore, the presence of this pathology is likely missed during its clinical course. A thorough history, including information regarding physical activity tolerance, combined with exercise and pulmonary testing procedures is necessary to determine whether a patient with TBI has cardiorespiratory dysfunction, including HAD and/or VIDD.

Exercise testing may be especially useful in identifying cardiorespiratory dysfunction in patients with TBI, since signs and symptoms of cardiorespiratory deficits may not be readily recognizable during the sedentary or low-intensity activities in which they are normally engaged. In the presence of cardiorespiratory dysfunction, $\dot{V} \mathrm{O}_{2 \text { peak }}$, which is the highest volume of oxygen consumption $\left(\mathrm{VO}_{2}\right)$ attained during high-intensity exercise testing, should be decreased. Since pre-TBI baseline data are not available for most patients, $\dot{V} \mathrm{O}_{2 \text { peak }}$ data generally should be interpreted in the context of age- and sex-specific normative reference ranges (e.g., Kaminsky et al. [82]). If diaphragmatic dysfunction is present, decreased tidal volume would be expected, which would necessitate an increased respiratory rate to meet ventilation demands [17]. Since this combination should result in increased dead space ventilation, and thus decreased gas exchange for a given minute ventilation (VE), $\mathrm{VE} / \mathrm{V} \mathrm{O}_{2}$ and $\mathrm{VE} / \dot{V} \mathrm{CO}_{2}$ (carbon dioxide consumption) ratios would be expected to be greater than those of a healthy population. Indeed, the relationship between $\mathrm{VE}$ and $\dot{V} \mathrm{O}_{2}$ is disrupted in patients during peak exercise with diaphragmatic paralysis [16], and animal models suggest this is due to increased metabolic requirements for ventilation [84]. Initially, one could expect these abnormal ventilatory responses to become magnified as submaximal exercise intensity increases. However, with a diaphragmatic limitation, maximal VE would be expected to be substantially reduced [16]. With greater ventilation necessary to achieve a given $\dot{V} \mathrm{O}_{2}$, increased respiratory muscle activity would be necessary at a given workload, which would therefore increase cardiovascular demand. This could theoretically increase heart rate (HR) and blood lactate at submaximal intensities. Oxyhemoglobin desaturation (i.e., pulse oximeter measurement $<92 \%$ ) during exercise has not been observed in patients with unilateral or bilateral diaphragmatic paralysis [16, 85], but it is unclear whether other co-morbidities could induce this during exercise in patients with moderate-to-severe TBI. 


\subsection{Exercise Testing}

Cardiorespiratory responses to exercise are severely compromised in the months following moderate-to-severe TBI and remain so years afterwards, as summarized in Table 1 . In Table 1, we included only studies that objectively measured $\dot{V} \mathrm{O}_{2}$ during exercise, and focused on patients with moderateto-severe TBI. Studies that included patients with mild TBI as $>50 \%$ of the sample were not included. If TBI severity was not stated, it was assumed that patients who were in a post-injury coma, described as having "brain damage", or recruited from an inpatient neurological rehabilitation center or long-term care facility had a history of moderateto-severe TBI. For datasets that included other neurological conditions (e.g., cerebrovascular accident), only those that had a sample $>80 \%$ moderate-to-severe TBI were included. When a given research group published more than one study, attempts were made to determine if there was any overlap between samples through evaluating the methods sections (i.e., specific mentions of overlap, institutional review board protocol numbers, and data collection dates), as well as attempted personal communication with corresponding authors.

In ten studies involving 203 patients (127 men, 41 women, 35 sex not reported; mean age $\sim 31$ years) at various post-injury timepoints, the weighted mean (standard deviation) of $\dot{V} \mathrm{O}_{2 \text { peak }}$ was $24.6(6.2) \mathrm{mL} \mathrm{O}_{2} / \mathrm{kg} / \mathrm{min}$. Though a comparison of this average $\dot{V} \mathrm{O}_{2 \text { peak }}$ to normative values is difficult due to mixed-sex data ( $75 \%$ men), many of the values reported would fall below the fifth percentile for healthy individuals in their respective age groups [82]. This substantial reduction in cardiorespiratory capacity equates to $65-75 \%$ of predicted $[10,11]$ and is consistently lower than sedentary healthy individuals in studies using a control group $[12,86]$. However, there may be substantial inter-individual variation within this patient population, depending on injury severity and time since initial injury. For instance, Chin et al. [87] report the highest group mean for $\dot{V} \mathrm{O}_{2 \text { peak }}$ $(37.1 \mathrm{~mL} \mathrm{O} / \mathrm{kg} / \mathrm{min}$ ) of any of the included studies, and their representative figure is that of a patient who achieved a $\dot{V} \mathrm{O}_{2 \text { peak }} \sim 55 \mathrm{~mL} \mathrm{O}_{2} / \mathrm{kg} / \mathrm{min}$ [87].

In many of the studies examining aerobic capacity, respiratory exchange ratios (RERs) indicated that patients had provided sufficient effort for a valid measurement (i.e., RER > 1.10), and thus were not limited by other factors (e.g., motivation). However, it is striking that four studies (across two research teams) reported RER at peak exercise $\geq 1.20$ [12, 86-88], with Chin et al. [87] reporting a mean of 1.35. These values exceed that expected from other factors that elevate maximal RER in healthy patients, such as diet [89], and from populations known to have poor ventilation and pulmonary gas exchange $[90,91]$. It is unknown whether these high RER values reflect a combination of ventilatory and metabolic issues in this patient population (e.g., hypercapnia due to increased buffering of hydrogen ions formed during glycolysis, altered renal acid-base balance), a mismatch between volitional exercise tolerance and cardiorespiratory capacity, dietary factors, or measurement error.

The absolute $\dot{V} \mathrm{O}_{2}$ at which the anaerobic threshold occurs has been demonstrated to be reduced in patients with TBI compared with healthy controls [86]. However, it is noteworthy that the relative intensity at which anaerobic threshold occurred was lower in patients with TBI $\left(\sim 52 \% \dot{V} \mathrm{O}_{2 \text { peak }}\right)$ than in healthy sedentary controls $\left(\sim 60 \% \dot{V} \mathrm{O}_{2 \text { peak }}\right)$ [86], and a similar relative intensity $\left(\sim 51 \% \dot{V} \mathrm{O}_{2 \text { peak }}\right)$ was reported in a separate study without a control group [87]. As exercise intensity increases beyond the anaerobic threshold, glycolytic metabolism would be expected to substantially increase and further drive ventilation. Together, these metabolic and respiratory stressors would be expected to increase the rating of perceived exertion substantially and lead to fatigue. As such, the reduced absolute and relative intensity at which anaerobic threshold occurs in this patient population may serve as a key barrier to physical activity participation.

VE may be decreased at anaerobic threshold [86] and during maximal exercise $[12,86]$. The $\mathrm{VE} / \dot{V} \mathrm{O}_{2}$ ratio may be significantly elevated in TBI patients during submaximal exercise [9], which strongly suggests compromised pulmonary function, though this is not consistent across studies [12, 86]. Impaired pulmonary function during exercise is consistent with an earlier cross-sectional study which revealed lung capacity and pulmonary function are reduced $~ 25-40 \%$ in patients who have recovered from TBI compared with healthy controls [9]. These pulmonary function deficits are present despite normal functional residual capacity and are not responsive to bronchodilators, which implicates respiratory muscle weakness [9]. Though the data seem convincing, this seems to be the only published report of spirometry/ pulmonary function evaluation in patients with TBI without other known major respiratory complications (e.g., tracheotomy, lung resection, etc.). Given that patients with moderate-to-severe TBI are prime candidates for VIDD, pulmonary deficits at rest and exercise (i.e., decreased VE and increased $\mathrm{VE} / \dot{V} \mathrm{O}_{2}$ at submaximal intensities) and substantially decreased aerobic capacity (i.e., $\dot{V} \mathrm{O}_{2 \text { peak }}$ ) are likely attributable to at least some degree of unaddressed diaphragmatic dysfunction.

Existing data do seem convincing in demonstrating cardiorespiratory deficits in this patient population, but there are some limitations to be aware of. Though many of these studies exclusively examine moderate-to-severe TBI [88, 92-94], a few datasets do include a relatively small number of patients with mild TBI $[12,13,86,87]$ or non-traumatic brain injuries [10, 11, 95]. Given that patients with mild TBI are unlikely to have received mechanical ventilation or experienced long inpatient stays, these less-injured individuals 


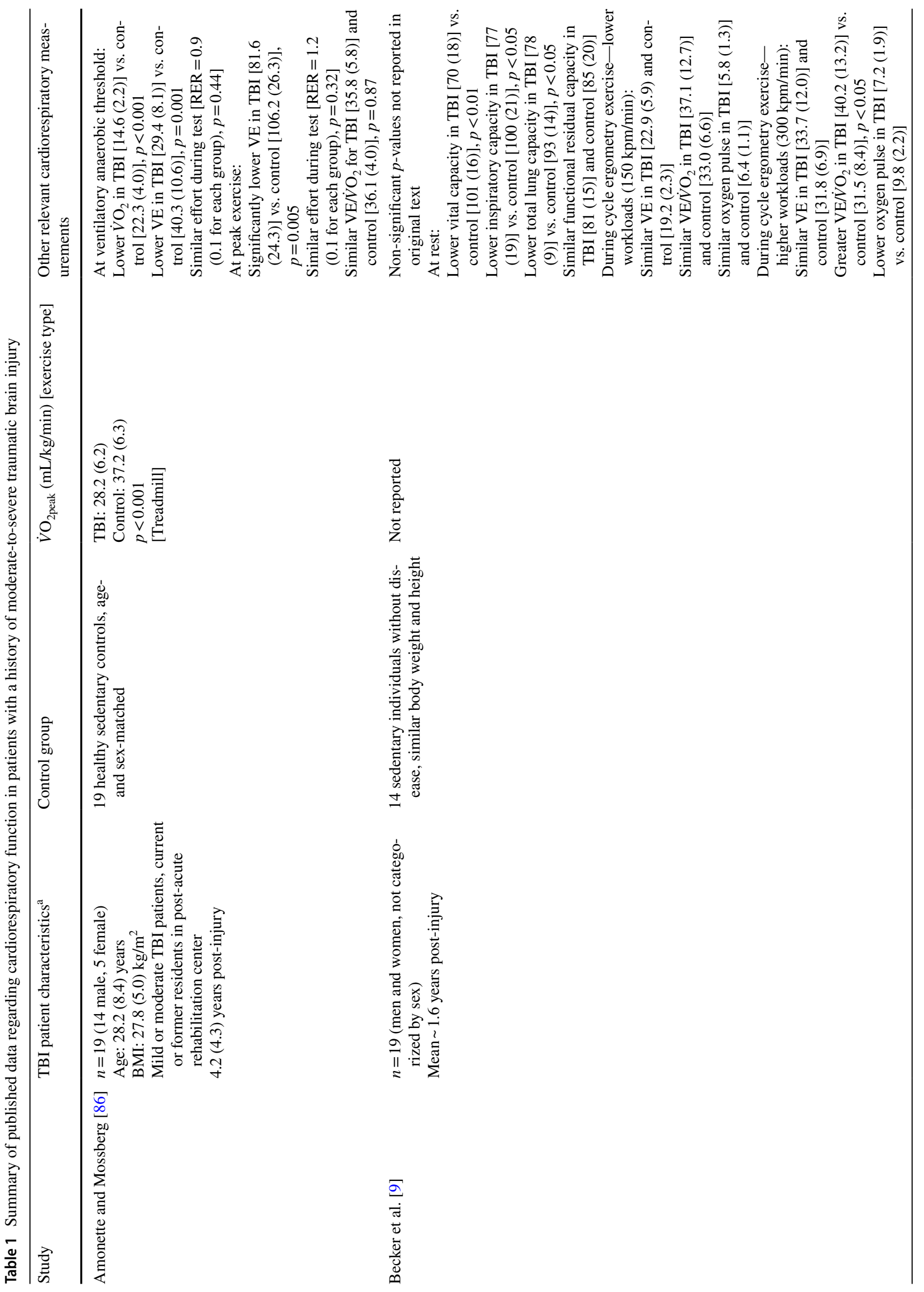




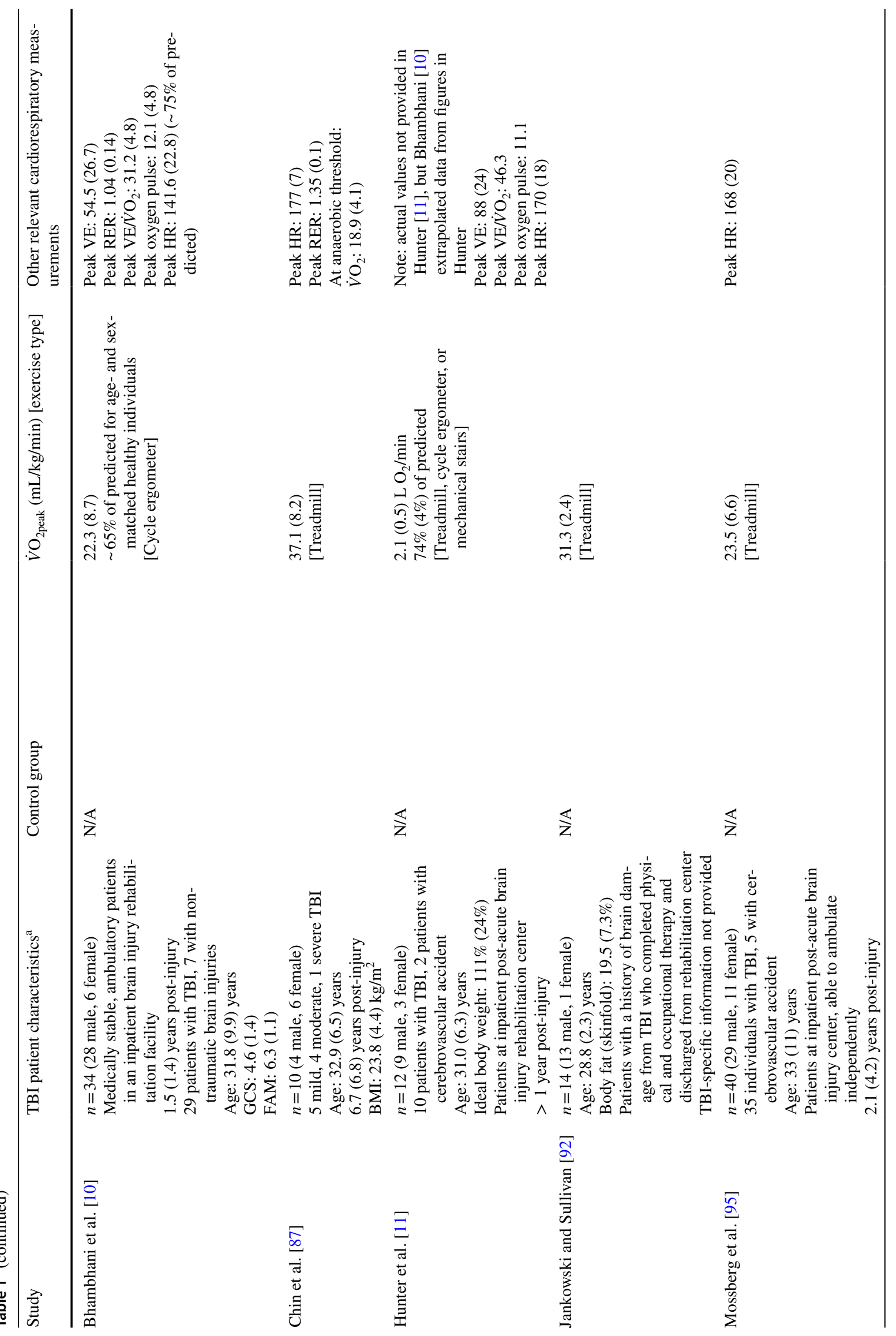



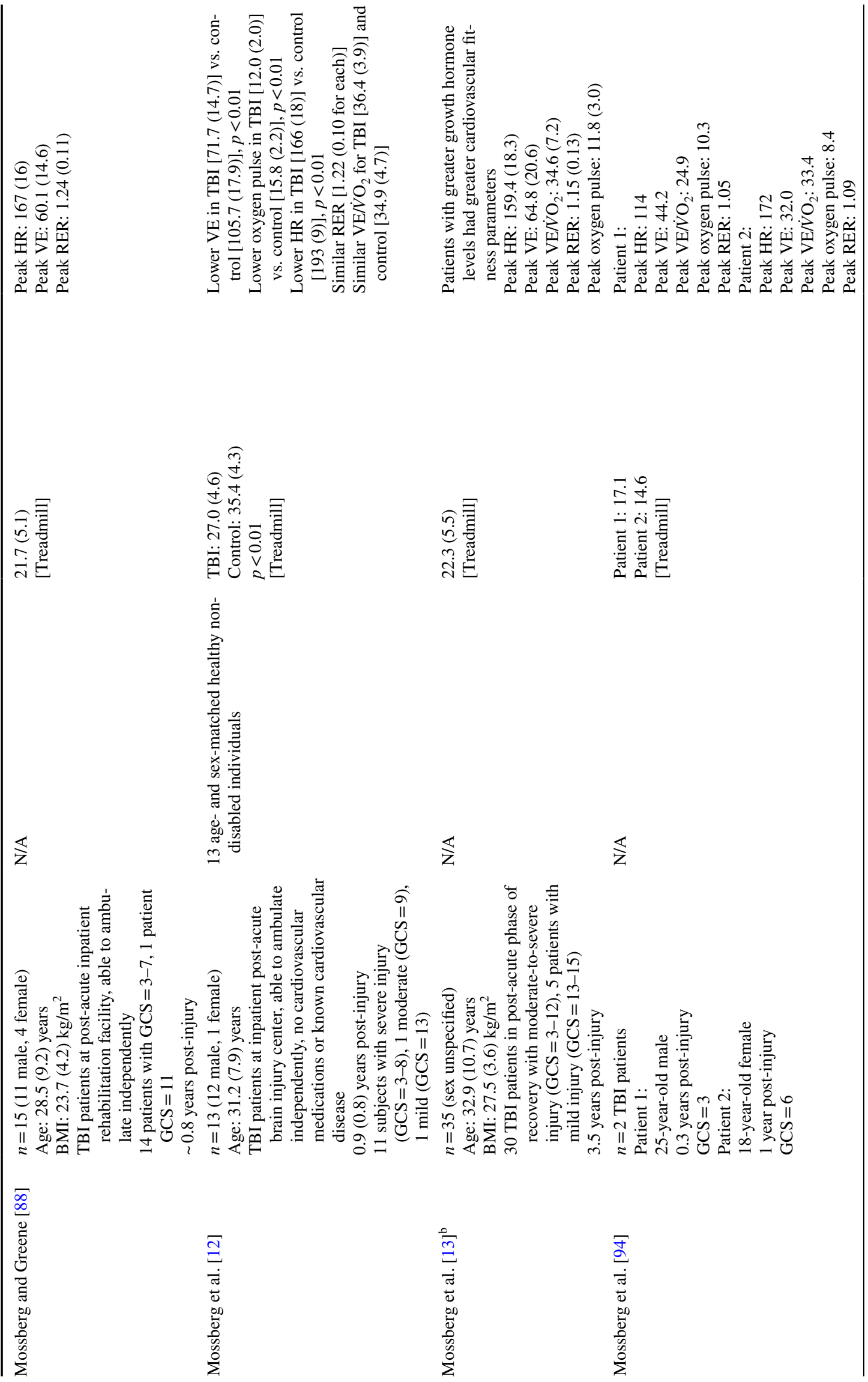
are not necessarily representative of the moderate-to-severe patient population. Aside from intermixing patient populations, there is considerable variation of the duration since initial injury within many studies. Therefore, it is difficult to determine how injury severity and the recovery period ultimately influence cardiorespiratory dysfunction. Though a number of different research groups have found similar results, it must be noted that the majority of datapoints come from various studies by Mossberg et al. [12, 13, 88, 93-95, $111]$, and it is not known whether each paper represents a unique dataset or if there is overlap in patients between studies. Thus, there is a need for further research in examining physiologic responses to exercise testing in this patient population.

\subsection{Diaphragmatic Function Evaluation}

An unusually poor exercise tolerance and response to exercise training in a patient with TBI may suggest the presence of VIDD. A detailed description of the diagnosis of VIDD is beyond the scope of this article, and the American Thoracic Society/European Respiratory Society's joint statement on respiratory muscle testing provides detailed information regarding measurement of diaphragmatic function [96]. Briefly, inspiratory pressure during phrenic nerve stimulation can provide insight regarding the diaphragm's ability to generate force. While this is the gold standard technique, there are multiple logistical barriers that preclude it from being a commonly utilized procedure. Standard pulmonary function testing can provide some insight into a patient's ability to generate inspiratory pressure, though this is effort dependent and does not test the diaphragm in isolation from other respiratory muscles. Additionally, there may be value in performing pulmonary function testing in both the upright and supine positions [97]. Fluoroscopy and ultrasound can be used to determine movement of the diaphragm, as well as its length and thickness across various lung volumes [96]. Unfortunately, these diaphragmatic assessments do not appear to be routinely provided to those with TBI who receive mechanical ventilation.

\subsection{Autonomic Nervous System Function}

A number of different measurements have been used to evaluate autonomic nervous system status in patients with moderate-to-severe TBI, including HR variability (HRV), blood pressure variability, and baroreflex sensitivity [98]. However, these measurements are generally used for prognostic information during the acute or sub-acute stages of injury [100], rather than as a component of cardiorespiratory functional evaluation during the chronic stage. There are limited data reporting measurements of autonomic nervous system function in ambulatory survivors of moderate-to-severe TBI, 
and the literature in this realm is currently limited to children and adolescents. In children, HR is greater and HRV is lower, both at rest and during exercise, $3-5$ years following severe TBI [101, 102]. Similar HR and HRV results were reported in a mixed population of brain-injured adolescents (including both traumatic and non-traumatic injuries) [98].

HRV data can be relatively easy to record using a standard HR monitor: there are a multitude of different parameters used to evaluate HRV, indicative of different aspects of autonomic function [103, 104], and a variety of different procedures to collect and analyze the data [105]. Although resting and exercise measurements of HRV may provide some insight into the status of the autonomic nervous system, and potentially cardiorespiratory function, it remains unclear how to apply these data in evaluating and managing this patient population in a TBI rehabilitation setting. There is growing interest in using biofeedback to modify abnormal HRV status, based on successes in healthy populations [106]. Though much of this work has focused on patients with mild TBI (i.e., post-concussion syndrome), one recent study demonstrated a single session of HRV biofeedback was effective in increasing multiple HRV parameters in patients with a history of severe TBI [107]. Other highly relevant measurements of autonomic nervous system function, such as arterial pulse wave characteristics [99], have been studied in relation to mild TBI, but their applicability to patients with moderate-to-severe TBI remain unknown.

\section{Management of Cardiorespiratory Dysfunction in Patients with Moderate-to-Severe TBI}

Although impaired cardiorespiratory function and subsequent poor functional outcomes indicative of VIDD and HAD are common in patients with TBI, these issues receive limited attention from researchers and are not adequately considered in any phase of TBI patient care [44]. Management of patients with TBI initially focuses upon lifesaving care, and later aims to restore functional capabilities. Inpatient and outpatient rehabilitation generally address neurologic deficits. While some cardiorespiratory functional assessments may be performed, this is a relatively minor component of evaluation and management in this patient population. Though outpatient rehabilitation may include some physical activity to counter this deconditioning, improvement is highly variable and may be very limited, leading to poor cardiorespiratory fitness $[10,44]$.

It is important for clinicians not to incorrectly attribute an observation of improved physical function to an improvement in cardiorespiratory function during typical rehabilitation. For instance, patients with TBI (mean 2.1 years post-injury) who underwent rehabilitation that included
15-20 min of low-intensity aerobic exercise for three sessions per week significantly increased treadmill walking time and movement efficiency but did not improve $\dot{V} \mathrm{O}_{2 \text { peak }}$ over a mean treatment time of 17.7 weeks [95]. This demonstrates that patients who may appear to have greater function (i.e., prolonged treadmill time) following rehabilitation do not necessarily have improved cardiorespiratory function. This may be due to insufficient exercise training stimulus, such as intensity and duration of each individual training session. The observed improvements in functional outcomes are likely related to peripheral adaptations to the physical activity, including skeletal muscle metabolism, rather than improvement in cardiorespiratory capacity - an outcome seen in other patient populations undergoing exercise training [110]. Thus, these patients may remain at increased risk of various co-morbidities associated with the cardiovascular and respiratory systems, and may also be more likely to gravitate towards sedentary behaviors.

\subsection{Exercise Training}

There is evidence that patients with TBI can positively respond to intentional exercise training, though such targeted cardiorespiratory programming is generally not part of standard inpatient or outpatient rehabilitation [111, 112]. Indeed, patients with TBI who exercise report better general health and emotional health than patients who do not exercise [113]. Approximately 3 months of a structured exercise training program has been demonstrated to improve $\dot{V} \mathrm{O}_{2 \text { peak }}$ and decrease resting HR in patients with moderate-to-severe $[11,114,115]$ and mild-to-severe TBI [87]. Studies with less structured programs have also been found to improve $\dot{V} \mathrm{O}_{2 \text { peak }}$ [92]. In addition, case series have demonstrated similar effects of post-TBI exercise training on $\dot{V} \mathrm{O}_{2 \text { peak }}[94]$ and found reductions in HR and reduced rating of perceived exertion for a given exercise intensity [116]. Exercise training has also been demonstrated to substantially increase absolute and relative $\dot{V} \mathrm{O}_{2}$ at anaerobic threshold, while increasing work rate and duration at this point [87]. Improvements in these parameters should reduce fatigue, and this has been confirmed through questionnaires examining fatigue severity [87].

Although improvements in $\dot{V} \mathrm{O}_{2 \text { peak }}$ have been noted in those with low baseline values, exercise training was insufficient to restore $\dot{V} \mathrm{O}_{2 \text { peak }}$ to that of healthy individuals and did not improve ventilatory efficiency [11]. This suggests that exercise training must be viewed as a longer-term part of rehabilitation, as the full benefits cannot be achieved within 12 weeks. It also is possible that typical exercise training does not sufficiently address underlying diaphragmatic dysfunction in patients who have been mechanically ventilated. Aerobic exercise at an intensity of $70-85 \%$ of age-predicted maximal HR for 30-40 min three to four times per week is 
recommended by the American Heart Association [117], and these guidelines are commonly used in the rehabilitation of HAD. These goals may be very difficult to achieve for patients with diaphragmatic weakness and respiratory insufficiency resulting from VIDD. As such, VIDD likely accelerates and exacerbates HAD in persons with moderateto-severe TBI, intensifying physical activity intolerance and facilitating further cardiorespiratory deterioration. Therefore, targeted strategies for improving diaphragmatic function must be applied to patients with TBI following mechanical ventilation, as they are for critically ill and other patient populations who also receive mechanical ventilation $[33$, 34, 118].

While this paper is focused on the cardiorespiratory benefits of exercise training for patients with moderate-to-severe TBI, it must be noted that exercise training has also been demonstrated to be beneficial for improving emotional status in patients with moderate-to-severe TBI. Given the interrelationships between physical activity participation, emotional health, quality of life, and cardiorespiratory fitness in the general population and various clinical populations [119-121], it is important for clinicians to appreciate that the multifaceted benefits of exercise training may extend beyond typical indicators of exercise performance in this patient population. Even a single 30-min session of moderate or high intensity exercise can immediately reduce symptoms of depression and anxiety [122] and improve mood [123] in patients with a history of mild-to-moderate TBI. A recent systematic review found that exercise training programs can reduce depressive symptoms in the general TBI patient population [124]. Previously sedentary patients with mildto-severe TBI may experience long-term changes in mood state within 4 weeks of beginning an exercise training program [123]. The mood-related benefits of such multi-week exercise training programs exceed those from standard neurorehabilitation alone [125].

\subsection{Inspiratory Muscle Training}

Targeted inspiratory muscle training during rehabilitation has been demonstrated to be effective in various patient populations with diaphragmatic dysfunction, including improved quality of life in a mixed cohort of patients who have undergone mechanical ventilation ( 7-12 days) [20], and may also be valuable for patients with moderateto-severe TBI who have received mechanical ventilation. Twelve weeks (6 weeks supervised, 6 weeks unsupervised) of physical therapy emphasizing diaphragmatic breathing and coughing, combined with strength training exercise and functional movements, has been shown to improve 1-year survival and various functional outcomes in non-TBI patients who had undergone prolonged ( $~ 50$ days) mechanical ventilation [21]. Inspiratory muscle training has been demonstrated to improve diaphragmatic function compared to sham treatment following major heart surgery [126]. Likewise, 6 weeks of inspiratory muscle training results in diaphragmatic hypertrophy and increased aerobic performance compared to sham treatment in Paralympic athletes with motor-complete spinal cord injuries at the C5-C7 level [127]. Beyond the direct effects on the diaphragm itself, inspiratory muscle training may improve blood flow to the skeletal muscles while reducing sympathetically mediated peripheral vasoconstriction [128]. This has been observed in patients with chronic heart failure, who had improved diaphragm thickness and blood flow to arm and leg muscles during exercise following 4 weeks of inspiratory muscle training [129]. Similarly, 10 weeks of inspiratory muscle training reduced dyspnea, increased exercise capacity, and improved quality of life compared with controls in patients with chronic heart failure [130]. Nocturnal desaturation during sleep has also been demonstrated to improve compared to sham treatment following 10 weeks of inspiratory muscle training in patients with chronic obstructive pulmonary disease [131].

Inspiratory muscle training may theoretically begin during weaning from the ventilator [132], though cognitive and behavioral issues in patients with TBI may make this challenging to implement. Thus, based on successes in other patient populations with exercise intolerance and suboptimal diaphragmatic function, inspiratory muscle training may be recommended as soon as a patient with a history of TBI is capable of doing so. However, further interventional research in this population is needed.

\section{Conclusion}

High rates of cardiorespiratory-related morbidity and mortality $[7,8]$ combined with evidence for cardiorespiratory dysfunction [9, 10, 12, 13, 44, 95] indicate that cardiorespiratory health should be a priority topic of research in the moderate-to-severe TBI population. Thus, there is a need for those with expertise in exercise medicine to be part of the interdisciplinary team managing this medically complex patient population. Epidemiologic research is needed to further elucidate how cardiorespiratory health relates to long-term morbidity and mortality in patients with moderate-to-severe TBI, as has been performed in other patient populations. There is also a specific need for epidemiological studies exploring VIDD in this population, due to the commonalities with other deconditioned patient populations who have been mechanically ventilated and experienced long inpatient stays.

Cardiorespiratory fitness, including diaphragmatic dysfunction, is generally not addressed by current rehabilitation standards for the TBI population [26, 133]. Recognition of 
the significance of cardiorespiratory dysfunction in moderate-to-severe TBI may result in breakthroughs in medical and rehabilitative management to ultimately reduce healthcare costs, decrease complications and high mortality, and improve functional outcomes and quality of life. Likewise, healthcare providers with expertise in cardiorespiratory fitness evaluation and interventions should be an integral part of management for patients with TBI. Thus, future studies should also explore best practice precision medicine for TBI to determine if long-term targeted cardiorespiratory interventions positively impact morbidity, mortality, secondary complications, and quality of life.

\section{Compliance with Ethical Standards}

Funding No sources of funding were used to assist in the preparation of this article.

Conflict of interest Renee Hamel and James Smoliga declare that they have no conflicts of interest relevant to the content of this review.

\section{References}

1. Wilson L, Stewart W, Dams-O'Connor K, Diaz-Arrastia R, Horton L, Menon DK, et al. The chronic and evolving neurological consequences of traumatic brain injury. Lancet Neurol. 2017;16(10):813-25.

2. Maas AIR, Menon DK, Adelson PD, Andelic N, Bell MJ, Belli A, et al. Traumatic brain injury: integrated approaches to improve prevention, clinical care, and research. Lancet Neurol. 2017;16(12):987-1048.

3. Masel BE, DeWitt DS. Traumatic brain injury: a disease process, not an event. J Neurotrauma. 2010;27(8):1529-40.

4. Reis C, Wang Y, Akyol O, Ho WM, Ii RA, Stier G, et al. What's new in traumatic brain injury: update on tracking, monitoring and treatment. Int J Mol Sci. 2015;16(6):11903-65.

5. Ouellet MC, Beaulieu-Bonneau S, Morin CM. Sleep-wake disturbances after traumatic brain injury. Lancet Neurol. 2015;14(7):746-57.

6. Lu W, Cantor J, Aurora RN, Nguyen M, Ashman T, Spielman L, et al. Variability of respiration and sleep during polysomnography in individuals with TBI. NeuroRehabilitation. 2014;35(2):245-51.

7. Chan V, Mollayeva T, Ottenbacher KJ, Colantonio A. Clinical profile and comorbidity of traumatic brain injury among younger and older men and women: a brief research notes. BMC Res Notes. 2017;10(1):371.

8. Shavelle RM, Strauss D, Whyte J, Day SM, Yu YL. Long-term causes of death after traumatic brain injury. Am J Phys Med Rehabil. 2001;80(7):510-6.

9. Becker E, Bar-Or O, Mendelson L, Najenson T. Pulmonary functions and responses to exercise of patients following cranio cerebral injury. Scand J Rehabil Med. 1978;10(2):47-50.

10. Bhambhani Y, Rowland G, Farag M. Reliability of peak cardiorespiratory responses in patients with moderate to severe traumatic brain injury. Arch Phys Med Rehabil. 2003;84(11):1629-36.

11. Hunter M, Tomberlin J, Kirkikis C, Kuna ST. Progressive exercise testing in closed head-injured subjects: comparison of exercise apparatus in assessment of a physical conditioning program. Phys Ther. 1990;70(6):363-71.

12. Mossberg KA, Ayala D, Baker T, Heard J, Masel B. Aerobic capacity after traumatic brain injury: comparison with a nondisabled cohort. Arch Phys Med Rehabil. 2007;88(3):315-20.

13. Mossberg KA, Masel BE, Gilkison CR, Urban RJ. Aerobic capacity and growth hormone deficiency after traumatic brain injury. J Clin Endocrinol Metab. 2008;93(7):2581-7.

14. Khan A, Morgenthaler TI, Ramar K. Sleep disordered breathing in isolated unilateral and bilateral diaphragmatic dysfunction. J Clin Sleep Med. 2014;10(5):509-15.

15. Steier J, Jolley CJ, Seymour J, Kaul S, Luo YM, Rafferty GF, et al. Sleep-disordered breathing in unilateral diaphragm paralysis or severe weakness. Eur Resp J. 2008;32(6):1479-87.

16. Hart N, Nickol AH, Cramer D, Ward SP, Lofaso F, Pride NB, et al. Effect of severe isolated unilateral and bilateral diaphragm weakness on exercise performance. Am J Respir Crit Care Med. 2002;165(9):1265-70.

17. Bonnevie T, Gravier FE, Ducrocq A, Debeaumont D, Viacroze $\mathrm{C}$, Cuvelier A, et al. Exercise testing in patients with diaphragm paresis. Respir Physiolo Neurobiol. 2018;248:31-5.

18. Jaber S, Petrof BJ, Jung B, Chanques G, Berthet JP, Rabuel C, et al. Rapidly progressive diaphragmatic weakness and injury during mechanical ventilation in humans. Am J Respir Crit Care Med. 2011;183(3):364-71.

19. Medrinal C, Prieur G, Frenoy E, Robledo Quesada A, Poncet A, Bonnevie T, et al. Respiratory weakness after mechanical ventilation is associated with one-year mortality - a prospective study. Crit Care. 2016;20(1):231.

20. Bissett BM, Leditschke IA, Neeman T, Boots R, Paratz J. Inspiratory muscle training to enhance recovery from mechanical ventilation: a randomised trial. Thorax. 2016;71(9):812-9.

21. Chen S, Su CL, Wu YT, Wang LY, Wu CP, Wu HD, et al. Physical training is beneficial to functional status and survival in patients with prolonged mechanical ventilation. J Formos Med Assoc. 2011;110(9):572-9.

22. Levine S, Nguyen T, Taylor N, Friscia ME, Budak MT, Rothenberg $\mathrm{P}$, et al. Rapid disuse atrophy of diaphragm fibers in mechanically ventilated humans. N Engl J Med. 2008;358(13):1327-35.

23. Powers SK, Wiggs MP, Sollanek KJ, Smuder AJ. Ventilatorinduced diaphragm dysfunction: cause and effect. Am J Physiol Regul Integr Comp Physiol. 2013;305(5):R464-77.

24. Falvey JR, Mangione KK, Stevens-Lapsley JE. Rethinking hospital-associated deconditioning: proposed paradigm shift. Phys Ther. 2015;95(9):1307-15.

25. Kortebein P. Rehabilitation for hospital-associated deconditioning. Am J Phys Med Rehabil. 2009;88(1):66-77.

26. Umphred DA. Neurological rehabilitation. 6th ed. Maryland Heights: Mosby; 2012.

27. Vos PE. Traumatic brain injury. Somerset: Wiley Blackwell; 2014.

28. Krumholz HM. Post-hospital syndrome-an acquired, transient condition of generalized risk. N Engl J Med. 2013;368(2):100-2.

29. Friedrich O, Reid MB, Van den Berghe G, Vanhorebeek I, Hermans G, Rich MM, et al. The sick and the weak: neuropathies/myopathies in the critically ill. Physiol Rev. 2015;95(3):1025-109.

30. Goligher EC, Ferguson ND, Brochard LJ. Clinical challenges in mechanical ventilation. Lancet. 2016;387(10030):1856-66.

31. Sollanek KJ, Smuder AJ, Wiggs MP, Morton AB, Koch LG, Britton SL, et al. Role of intrinsic aerobic capacity and ventilator-induced diaphragm dysfunction. J Appl Physiol. 2015;118(7):849-57.

32. Daniel Martin A, Smith BK, Gabrielli A. Mechanical ventilation, diaphragm weakness and weaning: a rehabilitation perspective. Respir Physiol Neurobiol. 2013;189(2):377-83. 
33. Berger D, Bloechlinger S, von Haehling S, Doehner W, Takala J, Z'Graggen WJ, et al. Dysfunction of respiratory muscles in critically ill patients on the intensive care unit. J Cachexia Sarcopenia Muscle. 2016;7(4):403-12.

34. Supinski GS, Morris PE, Dhar S, Callahan LA. Diaphragm dysfunction in critical illness. Chest. 2018;153(4):1040-51.

35. Levine S, Biswas C, Dierov J, Barsotti R, Shrager JB, Nguyen $\mathrm{T}$, et al. Increased proteolysis, myosin depletion, and atrophic AKT-FOXO signaling in human diaphragm disuse. Am J Respir Crit Care Med. 2011;183(4):483-90.

36. Shanely RA, Zergeroglu MA, Lennon SL, Sugiura T, Yimlamai T, Enns D, et al. Mechanical ventilation-induced diaphragmatic atrophy is associated with oxidative injury and increased proteolytic activity. Am J Respir Crit Care Med. 2002;166(10):1369-74.

37. Testelmans D, Maes K, Wouters P, Gosselin N, Deruisseau $\mathrm{K}$, Powers S, et al. Rocuronium exacerbates mechanical ventilation-induced diaphragm dysfunction in rats. Crit Care Med. 2006;34(12):3018-23.

38. Hudson MB, Smuder AJ, Nelson WB, Bruells CS, Levine S, Powers SK. Both high level pressure support ventilation and controlled mechanical ventilation induce diaphragm dysfunction and atrophy. Crit Care Med. 2012;40(4):1254-60.

39. Tang H, Smith IJ, Hussain SN, Goldberg P, Lee M, Sugiarto S, et al. The JAK-STAT pathway is critical in ventilator-induced diaphragm dysfunction. Mol Med. 2015;19(20):579-89.

40. Hermans G, Agten A, Testelmans D, Decramer M, Gayan-Ramirez $\mathrm{G}$. Increased duration of mechanical ventilation is associated with decreased diaphragmatic force: a prospective observational study. Crit Care. 2010;14(4):R127.

41. Mehta Y, Vats M, Singh A, Trehan N. Incidence and management of diaphragmatic palsy in patients after cardiac surgery. Ind J Crit Care Med. 2008;12(3):91-5.

42. Patakas D, Tsara V, Zoglopitis F, Daskalopoulou E, Argyropoulou P, Maniki E. Nocturnal hypoxia in unilateral diaphragmatic paralysis. Respiration. 1991;58(2):95-9.

43. Martin AD, Joseph AM, Beaver TM, Smith BK, Martin TD, Berg $\mathrm{K}$, et al. Effect of intermittent phrenic nerve stimulation during cardiothoracic surgery on mitochondrial respiration in the human diaphragm. Crit Care Med. 2014;42(2):e152-6.

44. Hassett L, Moseley AM, Harmer AR. Fitness training for cardiorespiratory conditioning after traumatic brain injury. Cochrane Database Syst Rev. 2017;12:6123.

45. Theadom A, Rowland V, Levack W, Starkey N, WilkinsonMeyers L, McPherson K. Exploring the experience of sleep and fatigue in male and female adults over the 2 years following traumatic brain injury: a qualitative descriptive study. BMJ Open. 2016;6(4):e010453.

46. van Markus-Doornbosch F, Meesters J, Kraaij L, Wolterbeek R, Vliet Vlieland T. Fatigue and its relationship with physical activity in adolescents and young adults with traumatic brain injury: a cross-sectional study. Eur J Phys Rehabil Med. 2017;53(6):900-9.

47. Wickwire EM, Williams SG, Roth T, Capaldi VF, Jaffe M, Moline M, et al. Sleep, sleep disorders, and mild traumatic brain injury. What we know and what we need to know: findings from a national working group. Neurotherapeutics. 2016;13(2):403-17.

48. Zgaljardic DJ, Durham WJ, Mossberg KA, Foreman J, Joshipura $\mathrm{K}$, Masel BE, et al. Neuropsychological and physiological correlates of fatigue following traumatic brain injury. Brain Inj. 2014;28(4):389-97.

49. Wise EK, Mathews-Dalton C, Dikmen S, Temkin N, Machamer J, Bell K, et al. Impact of traumatic brain injury on participation in leisure activities. Arch Phys Med Rehabil. 2010;91(9):1357-62.

50. Hamilton M, Khan M, Clark R, Williams G, Bryant A. Predictors of physical activity levels of individuals following traumatic brain injury remain unclear: a systematic review. Brain Inj. 2016;30(7):819-28.

51. Goverover Y, Genova H, Smith A, Chiaravalloti N, Lengenfelder J. Changes in activity participation following traumatic brain injury. Neuropsychol Rehabil. 2017;27(4):472-85.

52. Pawlowski J, Dixon-Ibarra A, Driver S. Review of the status of physical activity research for individuals with traumatic brain injury. Arch Phys Med Rehabil. 2013;94(6):1184-9.

53. Parcell DL, Ponsford JL, Redman JR, Rajaratnam SM. Poor sleep quality and changes in objectively recorded sleep after traumatic brain injury: a preliminary study. Arch Phys Med Rehabil. 2008;89(5):843-50.

54. Ponsford JL, Parcell DL, Sinclair KL, Roper M, Rajaratnam SM. Changes in sleep patterns following traumatic brain injury: a controlled study. Neurorehabil Neural Repair. 2013;27(7):613-21.

55. Lequerica AH, Botticello AL, Lengenfelder J, Chiaravalloti N, Bushnik T, Dijkers MP, et al. Factors associated with remission of post-traumatic brain injury fatigue in the years following traumatic brain injury (TBI): a TBI model systems module study. Neuropsychol Rehabil. 2017;27(7):1019-30.

56. Cantor JB, Bushnik T, Cicerone K, Dijkers MP, Gordon W, Hammond FM, et al. Insomnia, fatigue, and sleepiness in the first 2 years after traumatic brain injury: an NIDRR TBI model system module study. J Head Trauma Rehabil. 2012;27(6):E1-14.

57. Gardani M, Morfiri E, Thomson A, O'Neill B, McMillan TM. Evaluation of sleep disorders in patients with severe traumatic brain injury during rehabilitation. Arch Phys Med Rehabil. 2015;96(9):1691-7.

58. Matthews EE, Signoracci GM, Stearns-Yoder K, Brenner LA. A qualitative study of sleep-wake disturbance among veterans with post-acute moderate to severe traumatic brain injury. J Head Trauma Rehabil. 2016;31(2):126-35.

59. Kempf J, Werth E, Kaiser PR, Bassetti CL, Baumann CR. Sleepwake disturbances 3 years after traumatic brain injury. J Neurol Neurosurg Psychiatry. 2010;81(12):1402-5.

60. Wiseman-Hakes C, Duclos C, Blais H, Dumont M, Bernard F, Desautels A, et al. Sleep in the acute phase of severe traumatic brain injury: a snapshot of polysomnography. Neurorehabil Neural Repair. 2016;30(8):713-21.

61. Castriotta RJ, Atanasov S, Wilde MC, Masel BE, Lai JM, Kuna ST. Treatment of sleep disorders after traumatic brain injury. J Clin Sleep Med. 2009;5(2):137-44.

62. Castriotta RJ, Wilde MC, Lai JM, Atanasov S, Masel BE, Kuna ST. Prevalence and consequences of sleep disorders in traumatic brain injury. J Clin Sleep Med. 2007;3(4):349-56.

63. Mantua J, Grillakis A, Mahfouz SH, Taylor MR, Brager AJ, Yarnell AM, et al. A systematic review and meta-analysis of sleep architecture and chronic traumatic brain injury. Sleep Med Rev. 2018;41:61-77.

64. Dube BP, Dres M. Diaphragm dysfunction: diagnostic approaches and management strategies. J Clin Med. 2016;5(12):113.

65. Baltzan MA, Scott AS, Wolkove N. Unilateral hemidiaphragm weakness is associated with positional hypoxemia in REM sleep. J Clin Sleep Med. 2012;8(1):51-8.

66. Holcomb EM, Schwartz DJ, McCarthy M, Thomas B, Barnett $\mathrm{SD}$, Nakase-Richardson R. Incidence, characterization, and predictors of sleep apnea in consecutive brain injury rehabilitation admissions. J Head Trauma Rehabil. 2016;31(2):82-100.

67. Bratton SL, Davis RL. Acute lung injury in isolated traumatic brain injury. Neurosurgery. 1997;40(4):707-12 (discussion 12).

68. Rosenthal G, Hemphill JC, Sorani M, Martin C, Morabito $\mathrm{D}$, Meeker M, et al. The role of lung function in brain tissue oxygenation following traumatic brain injury. J Neurosurg. 2008;108(1):59-65. 
69. Gilston A. Facial signs of respiratory distress after cardiac surgery. A plea for the clinical approach to mechanical ventilation. Anaesthesia. 1976;31(3):385-97.

70. Harrison-Felix C, Whiteneck G, Devivo MJ, Hammond FM, Jha A. Causes of death following 1 year postinjury among individuals with traumatic brain injury. J Head Trauma Rehabil. 2006;21(1):22-33.

71. Kulnik ST, Birring SS, Hodsoll J, Moxham J, Rafferty GF, Kalra L. Higher cough flow is associated with lower risk of pneumonia in acute stroke. Thorax. 2016;71(5):474-5.

72. Baguley IJ, Nicholls JL, Felmingham KL, Crooks J, Gurka JA, Wade LD. Dysautonomia after traumatic brain injury: a forgotten syndrome? J Neurol Neurosurg Psychiatry. 1999;67(1):39-43.

73. Deepika A, Devi BI, Shukla D, Sathyaprabha TN, Christopher R, Ramesh SS. Neuroimmunology of traumatic brain injury: a longitudinal study of interdependency of inflammatory markers and heart rate variability in severe traumatic brain injury. $\mathrm{J}$ Neurotrauma. 2018;35(10):1124-31.

74. King ML, Lichtman SW, Seliger G, Ehert FA, Steinberg JS. Heart-rate variability in chronic traumatic brain injury. Brain Inj. 1997;11(6):445-53.

75. Sykora M, Czosnyka M, Liu X, Donnelly J, Nasr N, Diedler $\mathbf{J}$, et al. Autonomic impairment in severe traumatic brain injury: a multimodal neuromonitoring study. Crit Care Med. 2016;44(6):1173-81.

76. Henden PL, Sondergaard S, Rydenhag B, Reinsfelt B, Ricksten SE, Aneman A. Can baroreflex sensitivity and heart rate variability predict late neurological outcome in patients with traumatic brain injury? J Neurosurg Anesthesiol. 2014;26(1):50-9.

77. Kahraman S, Dutton RP, Hu P, Stansbury L, Xiao Y, Stein DM, et al. Heart rate and pulse pressure variability are associated with intractable intracranial hypertension after severe traumatic brain injury. J Neurosurg Anesthesiol. 2010;22(4):296-302.

78. Lavinio A, Ene-Iordache B, Nodari I, Girardini A, Cagnazzi E, Rasulo F, et al. Cerebrovascular reactivity and autonomic drive following traumatic brain injury. Acta Neurochir Suppl. 2008;102:3-7.

79. Keren O, Yupatov S, Radai MM, Elad-Yarum R, Faraggi D, Abboud S, et al. Heart rate variability (HRV) of patients with traumatic brain injury (TBI) during the post-insult sub-acute period. Brain Inj. 2005;19(8):605-11.

80. Baguley IJ, Heriseanu RE, Felmingham KL, Cameron ID. Dysautonomia and heart rate variability following severe traumatic brain injury. Brain Inj. 2006;20(4):437-44.

81. Huang CT, Tsai YJ, Lin JW, Ruan SY, Wu HD, Yu CJ. Application of heart-rate variability in patients undergoing weaning from mechanical ventilation. Criti Care. 2014;18(1):R21.

82. Kaminsky LA, Arena R, Myers J. Reference standards for cardiorespiratory fitness measured with cardiopulmonary exercise testing: data from the Fitness Registry and the Importance of Exercise National Database. Mayo Clin Proc. 2015;90(11):1515-23.

83. Bassett DR Jr, Howley ET. Limiting factors for maximum oxygen uptake and determinants of endurance performance. Med Sci Sports Exerc. 2000;32(1):70-84.

84. DiMarco AF, Connors AF Jr, Kowalski KE. Gas exchange during separate diaphragm and intercostal muscle breathing. J Appl Physiol. 2004;96(6):2120-4.

85. Laroche CM, Carroll N, Moxham J, Green M. Clinical significance of severe isolated diaphragm weakness. Am Rev Respir Dis. 1988;138(4):862-6.

86. Amonette WE, Mossberg KA. Ventilatory anaerobic thresholds of individuals recovering from traumatic brain injury compared with noninjured controls. J Head Trauma Rehabil. 2013;28(5):E13-20.
87. Chin LM, Chan L, Woolstenhulme JG, Christensen EJ, Shenouda $\mathrm{CN}$, Keyser RE. Improved cardiorespiratory fitness with aerobic exercise training in individuals with traumatic brain injury. $\mathrm{J}$ Head Trauma Rehabil. 2015;30(6):382-90.

88. Mossberg KA, Greene BP. Reliability of graded exercise testing after traumatic brain injury: submaximal and peak responses. Am J Phys Med Rehabil. 2005;84(7):492-500.

89. Niekamp K, Zavorsky GS, Fontana L, McDaniel JL, Villareal DT, Weiss EP. Systemic acid load from the diet affects maximalexercise RER. Med Sci Sports Exerc. 2012;44(4):709-15.

90. Zavorsky GS, Christou NV, Kim DJ, Carli F, Mayo NE. Preoperative gender differences in pulmonary gas exchange in morbidly obese subjects. Obes Surg. 2008;18(12):1587-98.

91. Smith JR, Van Iterson EH, Johnson BD, Borlaug BA, Olson TP. Exercise ventilatory inefficiency in heart failure and chronic obstructive pulmonary disease. Int J Cardiol. 2019;1(274):232-6.

92. Jankowski LW, Sullivan SJ. Aerobic and neuromuscular training: effect on the capacity, efficiency, and fatigability of patients with traumatic brain injuries. Arch Phys Med Rehabil. 1990;71(7):500-4.

93. Mossberg KA, Fortini E. Responsiveness and validity of the sixminute walk test in individuals with traumatic brain injury. Phys Ther. 2012;92(5):726-33.

94. Mossberg KA, Orlander EE, Norcross JL. Cardiorespiratory capacity after weight-supported treadmill training in patients with traumatic brain injury. Phys Ther. 2008;88(1):77-87.

95. Mossberg KA, Kuna S, Masel B. Ambulatory efficiency in persons with acquired brain injury after a rehabilitation intervention. Brain Inj. 2002;16(9):789-97.

96. American Thoracic Society/European Respiratory Society. ATS/ ERS statement on respiratory muscle testing. Am J Respir Crit Care Med. 2002;166(4):518-624.

97. Laveneziana P, Nierat MC, LoMauro A, Aliverti A. A case of unexplained dyspnoea: when lung function testing matters! Breathe. 2018;14(4):325-32.

98. Sorek G, Shaklai S, Meyer S, Katz-Leurer M. Autonomic cardiac control response to walking and executive cognitive task in adolescents with acquired brain injury and typically developed controls. Brain Inj. 2018;32(6):770-5.

99. La Fountaine MF, Toda M, Testa AJ, Hill-Lombardi V. Autonomic nervous system responses to concussion: arterial pulse contour analysis. Front Neurol. 2016;7:13.

100. Hasen M, Almojuela A, Zeiler FA. Autonomic dysfunction and associations with functional and neurophysiological outcome in moderate/severe traumatic brain injury: a scoping review. $\mathbf{J}$ Neurotrauma. 2019;36(10):1491-504.

101. Katz-Leurer M, Rotem H, Shofer M, Meyer S. Pediatric cardioautonomic response to variable effort after severe traumatic brain injury. Brain Inj. 2016;30(10):1239-42.

102. Katz-Leurer M, Rotem $H$, Keren $O$, Meyer S. Heart rate and heart rate variability at rest and during exercise in boys who suffered a severe traumatic brain injury and typically-developed controls. Brain Inj. 2010;24(2):110-4.

103. Shaffer F, Ginsberg JP. An overview of heart rate variability metrics and norms. Front Public Health. 2017;5:258.

104. Billman GE, Huikuri HV, Sacha J, Trimmel K. An introduction to heart rate variability: methodological considerations and clinical applications. Front Physiol. 2015;6:55.

105. Gisselman AS, D'Amico M, Smoliga JM. Optimizing inter-session reliability of heart rate variability - the effects of artefact correction and breathing type. J Strength Cond Res. 2017. https ://doi.org/10.1519/JSC.0000000000002258.

106. Conder RL, Conder AA. Heart rate variability interventions for concussion and rehabilitation. Front Psychol. 2014;5:890.

107. Francis HM, Fisher A, Rushby JA, McDonald S. Reduced heart rate variability in chronic severe traumatic brain injury: 
association with impaired emotional and social functioning, and potential for treatment using biofeedback. Neuropsychol Rehabil. 2016;26(1):103-25.

108. Blake TA, McKay CD, Meeuwisse WH, Emery CA. The impact of concussion on cardiac autonomic function: a systematic review. Brain Inj. 2016;30(2):132-45.

109. Paniccia M, Verweel L, Thomas SG, Taha T, Keightley M, Wilson KE, et al. Heart rate variability following youth concussion: how do autonomic regulation and concussion symptoms differ over time postinjury? BMJ Open Sport Exerc Med. 2018;4(1):e000355.

110. Holland AE, Hill CJ, Conron M, Munro P, McDonald CF. Short term improvement in exercise capacity and symptoms following exercise training in interstitial lung disease. Thorax. 2008;63(6):549-54.

111. Mossberg KA, Amonette WE, Masel BE. Endurance training and cardiorespiratory conditioning after traumatic brain injury. J Head Trauma Rehabil. 2010;25(3):173-83.

112. Sullivan SJ, Richer E, Laurent F. The role of and possibilities for physical conditioning programmes in the rehabilitation of traumatically brain-injured persons. Brain Inj. 1990;4(4):407-14.

113. Gordon WA, Sliwinski M, Echo J, McLoughlin M, Sheerer MS, Meili TE. The benefits of exercise in individuals with traumatic brain injury: a retrospective study. J Head Trauma Rehabil. 1998;13(4):58-67.

114. Bhambhani Y, Rowland G, Farag M. Effects of circuit training on body composition and peak cardiorespiratory responses in patients with moderate to severe traumatic brain injury. Arch Phys Med Rehabil. 2005;86(2):268-76.

115. Bateman A, Culpan FJ, Pickering AD, Powell JH, Scott OM, Greenwood RJ. The effect of aerobic training on rehabilitation outcomes after recent severe brain injury: a randomized controlled evaluation. Arch Phys Med Rehabil. 2001;82(2):174-82.

116. Schwandt M, Harris JE, Thomas S, Keightley M, Snaiderman A, Colantonio A. Feasibility and effect of aerobic exercise for lowering depressive symptoms among individuals with traumatic brain injury a pilot study. J Head Trauma Rehabil. 2012;27(2):99-103.

117. Lobelo F, Rohm Young D, Sallis R, Garber MD, Billinger SA, Duperly J, et al. Routine assessment and promotion of physical activity in healthcare settings: a scientific statement from the American Heart Association. Circulation. 2018;137(18):e495-522.

118. De Jonghe B, Bastuji-Garin S, Durand MC, Malissin I, Rodrigues $\mathrm{P}$, Cerf C, et al. Respiratory weakness is associated with limb weakness and delayed weaning in critical illness. Crit Care Med. 2007;35(9):2007-15.

119. Ortega FB, Lee DC, Sui X, Kubzansky LD, Ruiz JR, Baruth $\mathrm{M}$, et al. Psychological well-being, cardiorespiratory fitness, and long-term survival. Am J Prev Med. 2010;39(5):440-8.

120. Kubzansky LD, Thurston RC. Emotional vitality and incident coronary heart disease: benefits of healthy psychological functioning. Arch Gen Psychiatry. 2007;64(12):1393-401.
121. Dugmore LD, Tipson RJ, Phillips MH, Flint EJ, Stentiford NH, Bone MF, et al. Changes in cardiorespiratory fitness, psychological wellbeing, quality of life, and vocational status following a 12 month cardiac exercise rehabilitation programme. Heart. 1999;81(4):359-66.

122. Hoffman JM, Bell KR, Powell JM, Behr J, Dunn EC, Dikmen S, et al. A randomized controlled trial of exercise to improve mood after traumatic brain injury. PM R. 2010;2(10):911-9.

123. Weinstein AA, Chin LMK, Collins J, Goel D, Keyser RE, Chan L. Effect of arobic exercise training on mood in people with traumatic brain injury: a pilot study. J Head Trauma Rehabil. 2017;32(3):E49-56.

124. Perry SA, Coetzer R, Saville CWN. The effectiveness of physical exercise as an intervention to reduce depressive symptoms following traumatic brain injury: a meta-analysis and systematic review. Neuropsychol Rehabil. 2018;13:1-15.

125. Driver S, Ede A. Impact of physical activity on mood after TBI. Brain Inj. 2009;23(3):203-12.

126. Kodric M, Trevisan R, Torregiani C, Cifaldi R, Longo C, Cantarutti $\mathrm{F}$, et al. Inspiratory muscle training for diaphragm dysfunction after cardiac surgery. J Thorac Cardiovasc Surg. 2013;145(3):819-23.

127. West CR, Taylor BJ, Campbell IG, Romer LM. Effects of inspiratory muscle training on exercise responses in Paralympic athletes with cervical spinal cord injury. Scand J Med Sci Sports. 2014;24(5):764-72.

128. Bissett B, Leditschke IA, Paratz JD, Boots RJ. Respiratory dysfunction in ventilated patients: can inspiratory muscle training help? Anaesth Intens Care. 2012;40(2):236-46.

129. Chiappa GR, Roseguini BT, Vieira PJ, Alves CN, Tavares A, Winkelmann ER, et al. Inspiratory muscle training improves blood flow to resting and exercising limbs in patients with chronic heart failure. J Am Coll Cardiol. 2008;51(17):1663-71.

130. Laoutaris I, Dritsas A, Brown MD, Manginas A, Alivizatos PA, Cokkinos DV. Inspiratory muscle training using an incremental endurance test alleviates dyspnea and improves functional status in patients with chronic heart failure. Eur J Cardiovasc Prev Rehabil. 2004;11(6):489-96.

131. Heijdra YF, Dekhuijzen PN, van Herwaarden CL, Folgering HT. Nocturnal saturation improves by target-flow inspiratory muscle training in patients with COPD. Am J Respir Crit Care Med. 1996;153(1):260-5.

132. Tonella RM, Ratti L, Delazari LEB, Junior CF, Da Silva PL, Herran A, et al. Inspiratory muscle training in the intensive care unit: a new perspective. J Clin Med Res. 2017;9(11):929-34.

133. Brasure M, Lamberty GJ, Sayer NA, Nelson NW, MacDonald $\mathrm{R}$, Ouellette J, et al. AHRQ comparative effectiveness reviews. multidisciplinary postacute rehabilitation for moderate to severe traumatic brain injury in adults. Rockville: Agency for Healthcare Research and Quality (US); 2012. 